\title{
APLIKASI ALAT UKUR DEBU BERBASIS SMS DAN ANALISIS MODEL DISPERSI GAUSS
}

\author{
S. Syahrorini ${ }^{1}$ dan A. Ahfas ${ }^{2}$ \\ ${ }^{1,2}$ Universitas Muhammadiyah Sidoarjo \\ E-mail: syahrorini@umsida.ac.id
}

\begin{abstract}
Air is an important component in this life, for it needs to be maintained air quality from air pollution. Degradation of air quality due to dust pollution can cause respiratory diseases. To facilitate the delivery of measurements of ambient air dust according to technological developments can use SMS. The design of SMS based measuring instrument using dust sensor gp2y1010auOf detects dust concentration, amplifier circuit, Arduino Uno microcontroller, SMS Gateway sim 900 and LCD (Liquid Crystal Display) module. Measurement applications in PG. Krembung Sidoarjo Jatim in Lemujut Village is $1800 \mathrm{~m}$ and Mojoruntut village is $1500 \mathrm{~m}$. The measurement results show the concentration of ambient air quality standard, so safe for the surrounding community. The concentration spreading pattern is smaller from the center of the chimney to the point of measurement.
\end{abstract}

Keywords: dust, sms, dispertion gaussian model

\begin{abstract}
ABSTRAK
Udara merupakan komponen penting dalam kehidupan ini, untuk itu perlu dijaga kualitas udara dari polusi udara. Degradasi kualitas udara karena polusi debu dapat menyebabkan penyakit pernapasan. Untuk memudahkan pengiriman pengukuran debu udara sesuai perkembangan teknologi dapat menggunakan SMS. Desain alat ukur berbasis SMS menggunakan sensor debu gp2y1010au0f untuk mendeteksi konsentrasi debu, rangkaian penguat, mikrokontroler Arduino Uno, modul SMS Gateway sim 900 dan LCD (Liquid Crystal Display). Aplikasi pengukuran dalam PG. Krembung Sidoarjo Jatim di Desa Lemujut adalah $1800 \mathrm{~m}$ dan di desa Mojoruntut adalah 1500 m. Hasil pengukuran menunjukkan konsentrasi kualitas udara sesuai standar, sehingga aman bagi masyarakat sekitar. Pola penyebaran konsentrasi lebih kecil dari pusat cerobong ke titik pengukuran.
\end{abstract}

Kata kunci: dust, sms, dispertion gaussian model

\section{PENDAHULUAN}

Peningkatan pembangunan industri konsekuensinya terjadi peningkatan limbah yang dikeluarkan oleh industri tersebut. Limbah industri berpotensi sebagai penyebab pencemaran udara, antara lain partikel debu, gas $\mathrm{SO}_{2}$, gas $\mathrm{NO}_{2}, \mathrm{CO}, \mathrm{NH}_{3}$ dan $\mathrm{HC}$ H.J. ${ }^{(1)}$. Pencemaran udara yang disebabkan partikel debu dapat mengakibatkan terjadinya penyakit pernafasan kronis seperti bronchitis, khronis, emifiesma paru, asma bronchial bahkan kanker paru ${ }^{(2)}$. Untuk itu kualitas udara perlu dijaga konsentrasinya sesuai baku mutu udara ambien dengan dipantau secara intensif. Pemantauan kualitas udara memerlukan dana yang cukup besar, waktu, tenaga, dan teknologi, untuk itu diperlukan sebuah alternatif dalam mempermudah melakukan pengukuran konsentrasi debu udara ambien menggunakan SMS gateway ${ }^{(3)}$. 
Alat ukur debu berbasis SMS gateway ini diaplikasikan pada area terdampak adanya debu. Tampilan hasil ukur konsentrasi melalui LCD, Mikrokontroller Arduino UNO sebagai kontroller, Kit Module SMS Gateway. Untuk keluaran kedua yaitu modul SMS gateway ${ }^{(4)}$.

Pola penyebaran debu dianalisis menggunakan analisis model dispersi gauss dan dilakukan overlay ${ }^{(5)}$. Penelitian ini bertujuan mengetahui pola penyebaran debu dari pusat cerobong pabrik gula terhadap area pengukuran.

\section{METODE}

Penelitian ini diawali dengan rancang bangun alat ukur debu berbasis SMS gateway, aplikasi pengukuran di area Pabrik Gula Krembung di Desa Lemujut berjarak 1800 m dari pusat cerobong pabrik Gula Krembung, dan Desa Mojoruntut berjarak $1500 \mathrm{~m}$ dari pusat cerobong Pabrik Gula Krembung. Selanjutnya untuk melihat pola penyebaran debu dianalisis menggunakan model dispersi gauss dengan simulasi komputer menggunakan matlab. Hasil simulasi komputer dilakukan overlay menggunakan google earth pada area pengukuran.

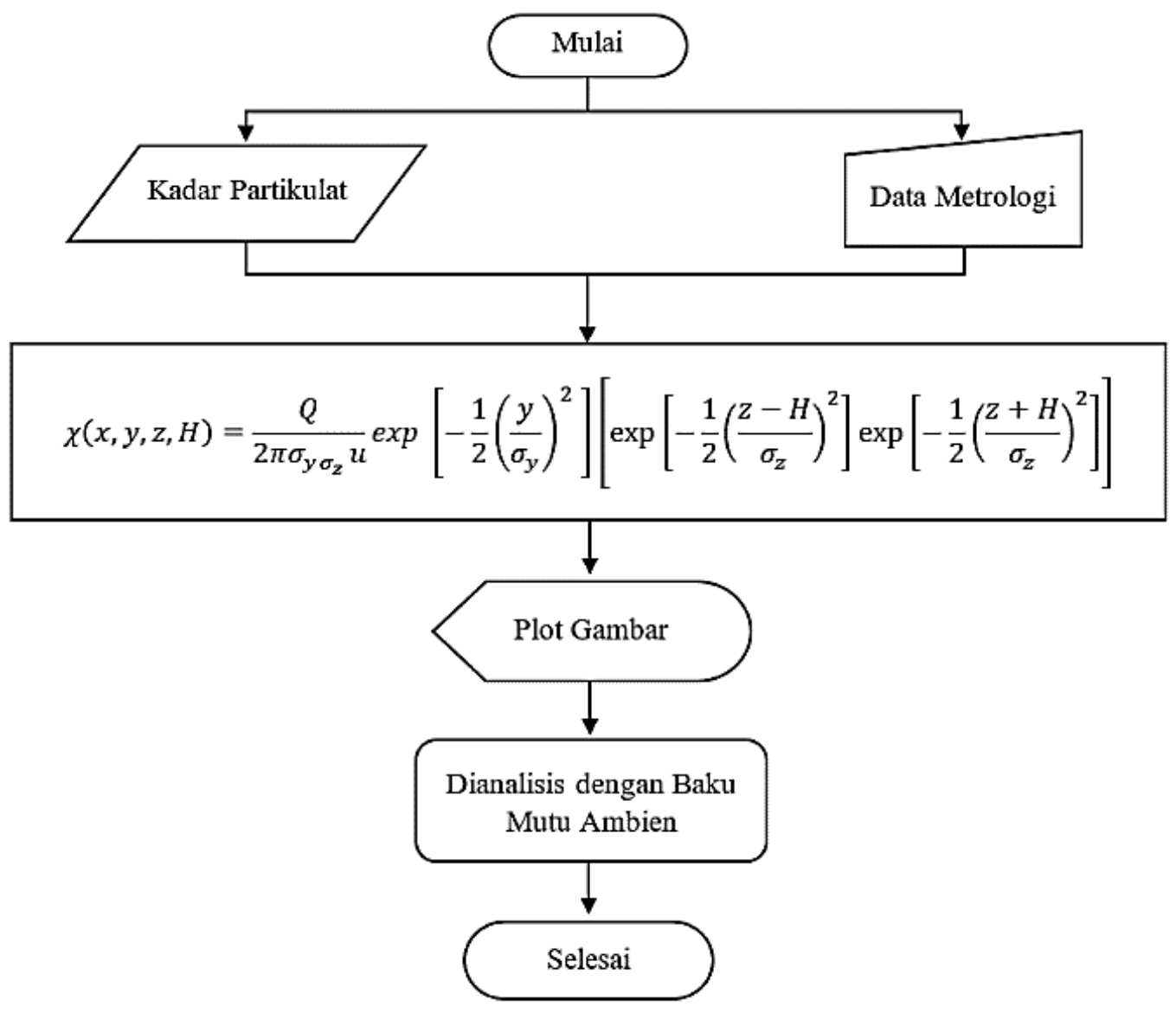

Gambar 1. Flowchart Simulasi Komputer

Gambar 1 menjelaskan urutan simulasi komputer, setelah mengukur kadar debu di area pengukuran, menentukan data meteorologi. Selanjutnya dilakukan proses simulasi komputer menggunakan program matlab untuk mendapatkan pola penyebaran debu dengan analisis model dispersi gauss.
Komponen yang digunakan dalam rancang bangun alat ukur debu adalah perakitan mikrokontroller arduino dan pemasangan komponen seperti : Modul SMS Gateway SIM 900A, DC to DC, Sensor Debu Sharp Type gp2y1010au0f. 


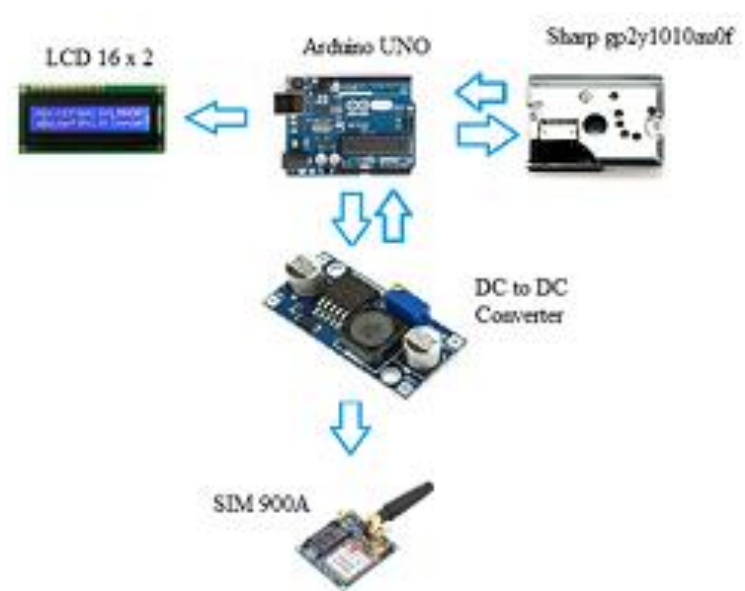

Gambar 2. Wiring Komponen ${ }^{(4)}$

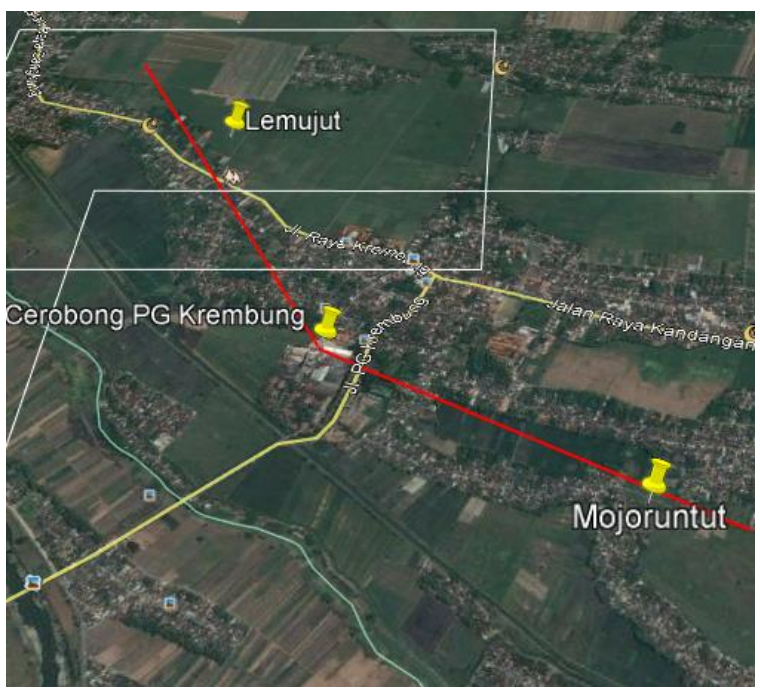

Gambar 3. Lokasi Pengukuran (Peta Area Pengukuran dengan Google Earth)

\section{HASIL DAN PEMBAHASAN}

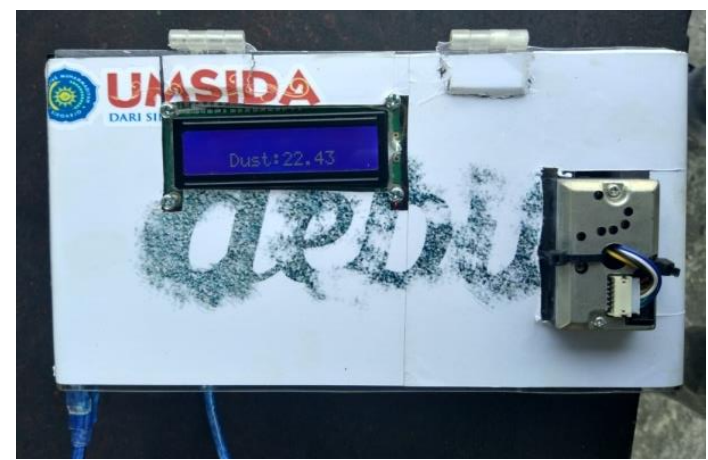

Gambar 4. Tampilan Hasil Pengukuran Desa Lemujut Pada LCD

Gambar 4 menunjukkan tampilan pengukuran Desa Lemujut yang ditampilkan pada layar LCD dengan konsentrasi debu sebesar 22,43 pada menit 15 pukul 12.58 .
Konsentrasi ini merupakan konsentrasi tertinggi pada saat pengukuran.
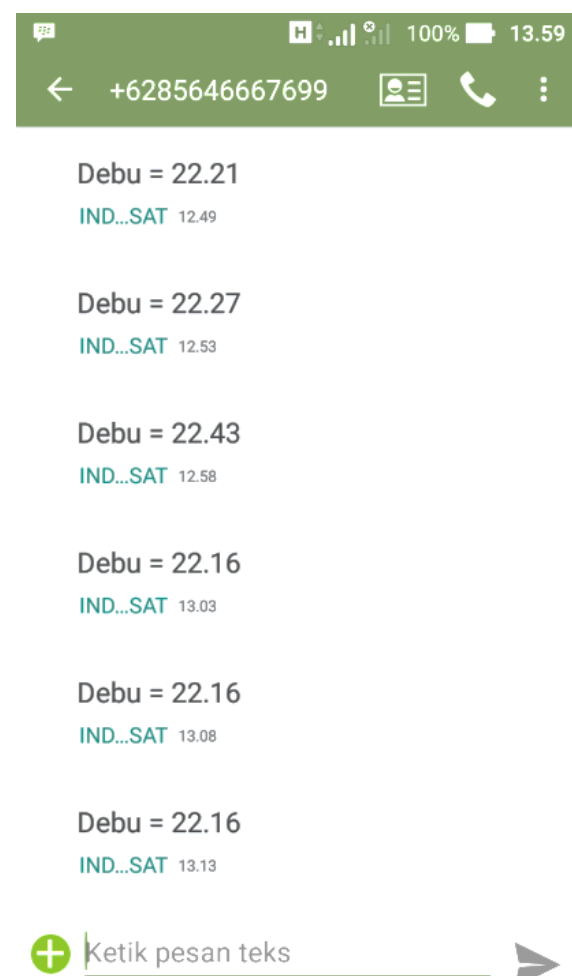

Gambar 5. SMS Gateway Hasil Pengukuran Desa Lemujut

Gambar 5 menunjukkan hasil pengukuran aplikasi SMS gateway di Desa Lemujut setiap lima menit dari pukul 12.4913.13 .

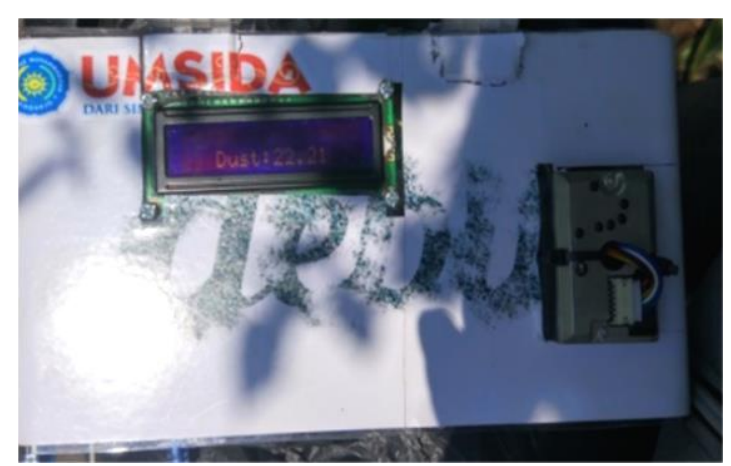

Gambar 6. Tampilan Hasil Pengukuran Desa Mojoruntut Pada LCD

Gambar 6 menunjukkan tampilan pengukuran Desa Mojoruntut yang ditampilkan pada layar LCD dengan konsentrasi debu sebesar 22,21 pada menit ke 10 pukul 14.10 . 


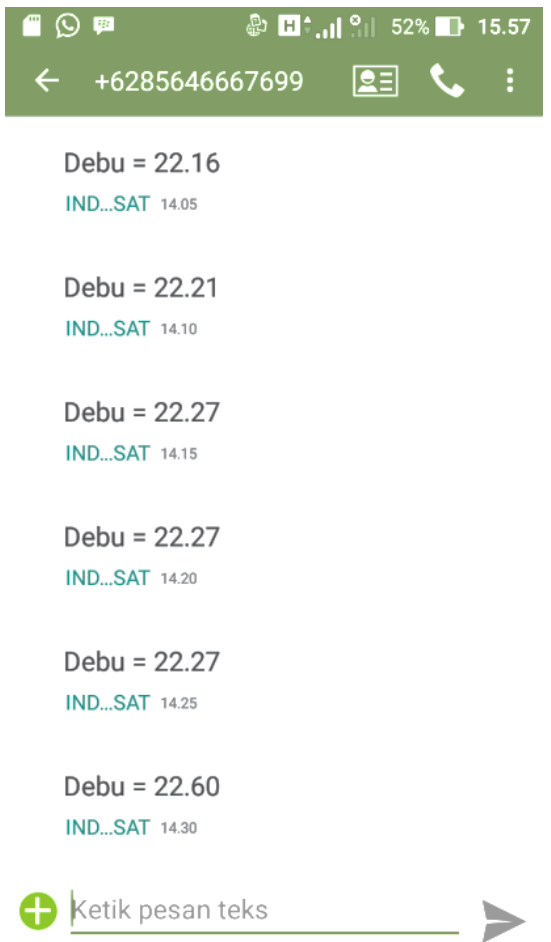

Gambar 7. SMS Gateway Hasil Pengukuran Desa Mojoruntut

Gambar 7 menunjukkan hasil pengukuran aplikasi SMS gateway di Desa Mojoruntut tiap lima menit dari pukul 14.0514.30. Konsentrasi tertinggi 22,60 pada pukul 14.30. Pada simulasi komputer menggunakan ketinggian stack $45 \mathrm{~m}$ untuk tiap kestabilitasan kelas A, B, C, D, E, dan F. Perhitungan variasi $\sigma y$ dan $\sigma \mathrm{z}$ pada $\mathrm{x}$ dengan searah angin (After Briggs, 1974; S.M Kavishwar et all, 2014), ditunjukkan pada Tabel 1. Parameter oy merupakan parameter penyebaran arah horizontal dalam satuan $\mathrm{m}$, parameter $\sigma \mathrm{z}$ merupakan parameter penyebaran vertikal dalam satuan $m$ dan $x$ merupakan jarak pengukuran dari pusat cerobong dalam satuan $\mathrm{m}$.
Tabel 1. Formulasi Interpolasi Parameter Dispersi

\begin{tabular}{clc}
\multicolumn{3}{c}{$\sigma_{\mathrm{y}}$ dan $\sigma_{\mathrm{z}}$} \\
Kelas & \multicolumn{1}{c}{ Nilai Parameter $\sigma_{y}$ dan $\sigma_{z}$} \\
\hline \multirow{2}{*}{ A } & $0,22 x(1$ & \multicolumn{1}{c}{$\sigma_{z}(\mathrm{~m})$} \\
& $+0,0001 x)^{-1 / 2}$ & \multicolumn{1}{c}{$0,20 \mathrm{x}$} \\
B & $0,16 x(1$ & \\
& $+0,0001 x)^{-1 / 2}$ & $0,12 \mathrm{x}$ \\
C & $0,11 x(1$ & $0,08 x(1$ \\
& $+0,0001 x)^{-1 / 2}$ & $+0,0002 x)^{-1 / 2}$ \\
D & $0,08 x(1$ & $0,06 x(1$ \\
& $+0,0001 x)^{-1 / 2}$ & $+0,0015 x)^{-1 / 2}$ \\
E & $0,06 x(1$ & $0,03 x(1$ \\
& $+0,0001 x)^{-1 / 2}$ & $+0,0003 x)^{-1 / 2}$ \\
F & $0,04 x(1$ & $0,016 x(1$ \\
& $+0,0001 x)^{-1 / 2}$ & $+0,0003 x)^{-1 / 2}$ \\
\hline
\end{tabular}

Tabel 2. Parameter $\sigma \mathrm{y}$ dan $\sigma z$ pada $\mathrm{x}=1500 \mathrm{~m}$

\begin{tabular}{cccc}
\hline Kelas & $\mathrm{x}(\mathrm{m})$ & $\sigma \mathrm{y}$ & $\sigma \mathrm{z}$ \\
\hline A & 1500 & 307,727 & 300 \\
$\mathrm{~B}$ & 1500 & 223,801 & 180 \\
C & 1500 & 153,863 & 111,901 \\
D & 1500 & 111,901 & 83,9254 \\
E & 1500 & 83,9254 & 41,9627 \\
F & 1500 & 55,9503 & 22,380111 \\
\hline
\end{tabular}

Tabel 2 menjelaskan parameter $\sigma y$ merupakan parameter penyebaran arah horizontal dan $\sigma \mathrm{z}$ merupakan parameter penyebaran vertikal pada jarak pengukuran $\mathrm{x}=1500 \mathrm{~m}$, yaitu jarak pengukuran dari pusat cerobong pabrik gula Krembung ke Desa Mojoruntut. Parameter ini digunakan sebagai data masukan simulasi komputer untuk mendapatkan pola penyebaran debu dengan analisis model dispersi gauss.

Tabel 3. Parameter $\sigma \mathrm{y}$ dan $\sigma \mathrm{z}$ Pada $\mathrm{x}=1800 \mathrm{~m}$

\begin{tabular}{cccc}
\hline Kelas & $\mathrm{x}(\mathrm{m})$ & $\sigma \mathrm{y}$ & $\sigma \mathrm{z}$ \\
\hline A & 1800 & 364,548 & 360 \\
B & 1800 & 265,125 & 216 \\
C & 1800 & 182,274 & 132,563 \\
D & 1800 & 132,563 & 99,4221 \\
E & 1800 & 99,4221 & 49,711 \\
F & 1800 & 66,2814 & 26,5125 \\
\hline
\end{tabular}


Tabel 3 menjelaskan parameter $\sigma y$ merupakan parameter penyebaran arah horizontal dan $\sigma \mathrm{z}$ merupakan parameter penyebaran vertikal pada jarak pengukuran $\mathrm{x}$ $=1800 \mathrm{~m}$, yaitu jarak pengukuran dari pusat cerobong pabrik gula Krembung ke Desa Lemujut. Selanjutnya parameter ini sebagai data masukan pada simulasi komputer untuk mendapatkan pola penyebaran debu pada Desa Lemujut dari pusat cerobong Pabrik Gula Krembung.

Berdasarkan perhitungan parameter $\sigma y$ dan $\sigma \mathrm{z}$ sesuai rumus Brings dari dua jarak pengukuran debu ambien di Desa Mojoruntut dan Desa Lemujut Krembung. Selanjutnya dari parameter tersebut dimasukkan ke simulasi komputer berdasarkan rumus dispersi Gauss model. Keluaran dari simulasi komputer ini ditampilkan dalam bentuk kontur dan grafik konsentrasi debu.

Tabel 4. Nilai Parameter Simulasi Komputer $\mathrm{x}=$ $1500 \mathrm{~m}$

\begin{tabular}{cc}
\hline PARAMETER & NILAI \\
\hline Laju Emisi (g/s) & 6,1 \\
Tinggi Stack Efektif H & 50 \\
$(\mathrm{~m})$ & 1 \\
Kecepatan Angin (m/s) & Barat \\
Arah Angin & 0 \\
Stack x (m) & 45 \\
Stack y (m) & 1500 \\
Xmax (m) & 400 \\
Ymax (m) & 32,7 \\
Temperatur (0C) & A, B, C, D, E dan \\
Kestabilan Atmosfer & F \\
\hline
\end{tabular}

Tabel 4 menunjukkan nilai parameter yang menjadi masukan pada simulasi komputer dengan analisis model dispersi gauss untuk $\mathrm{x}=1500 \mathrm{~m}$.

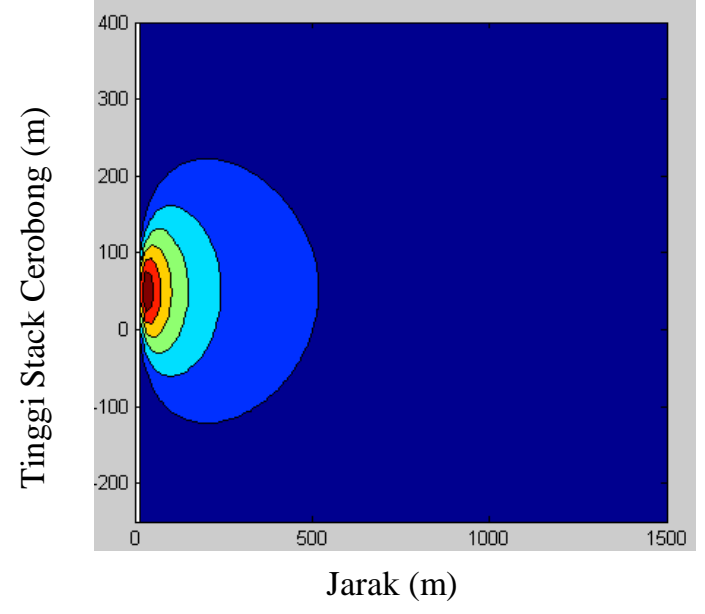

(A) Kontur Pola Penyebaran

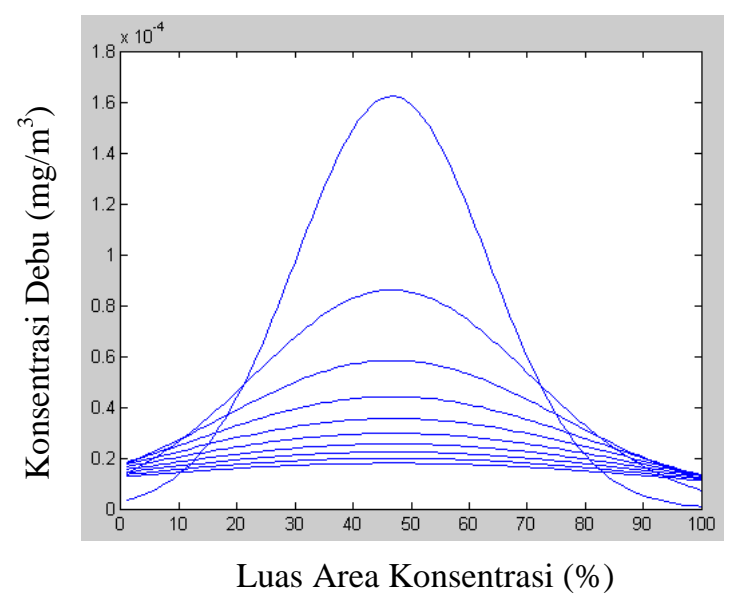

(B) Konsentrasi Debu

Gambar 8. (A) Kontur Pola Penyebaran Desa Mojoruntut, dan (B). Konsentrasi Pengukuran Desa Mojoruntut Kelas F

Gambar 8 (A) menunjukkan kontur dan konsentrasi debu jarak pengukuran $\mathrm{x}=1500 \mathrm{~m}$ dari pusat cerobong pabrik gula Krembung yaitu Desa Mojoruntut pada stabilitas atmosfer F (stabil). Pada stabilitas atmosfer kelas F (stabil) ini pola penyebaran debu makin melebar dan jelas kelihatan tiap segmennya. Dengan jumlah segmen degradasi warna lebih banyak yakni enam segmen degradasi warna.

(B) Konsentrasi penyebaran lebih besar dibandingkan pada stabilitas atmosfer kelas A, $\mathrm{B}, \mathrm{C}$ dan $\mathrm{D}$, yakni 1,7 x 10-4 dengan interval $0,2 \times 10-4$. 
Tabel 5. Nilai Parameter Simulasi Komputer $\mathrm{x}=$ $1800 \mathrm{~m}$

\begin{tabular}{cc}
\hline PARAMETER & NILAI \\
\hline Laju Emisi (g/s) & 6,1 \\
Tinggi Stack Efektif H & 50 \\
$(\mathrm{~m})$ & 1 \\
Kecepatan Angin (m/s) & Barat \\
Arah Angin & 0 \\
Stack x (m) & 45 \\
Stack y (m) & 1800 \\
Xmax (m) & 400 \\
Ymax (m) & 32,7 \\
Temperatur (0C) & A, B, C, D, E dan \\
Kestabilan Atmosfer & F \\
\hline
\end{tabular}

Tabel 5 menunjukkan menunjukkan nilai parameter yang menjadi masukan pada simulasi komputer dengan analisis model dispersi gauss untuk $\mathrm{x}=1800 \mathrm{~m}$.

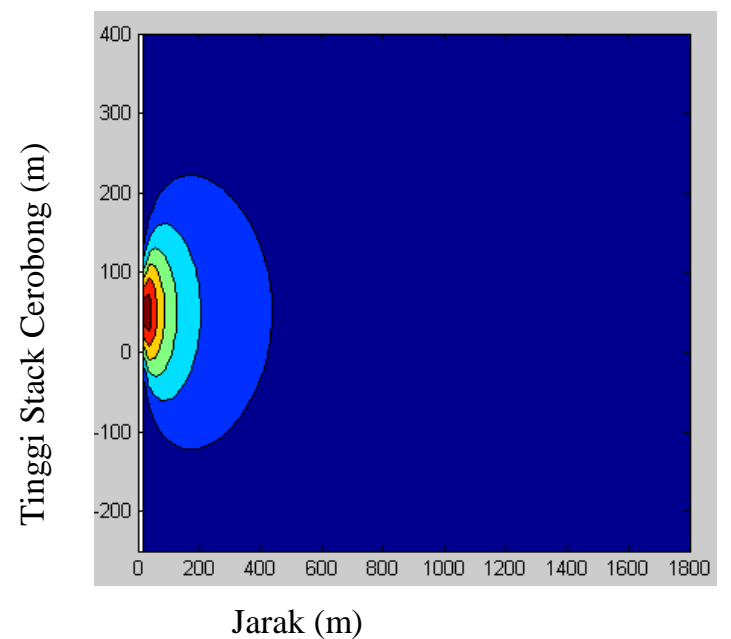

(A) Kontur Pola Penyebaran

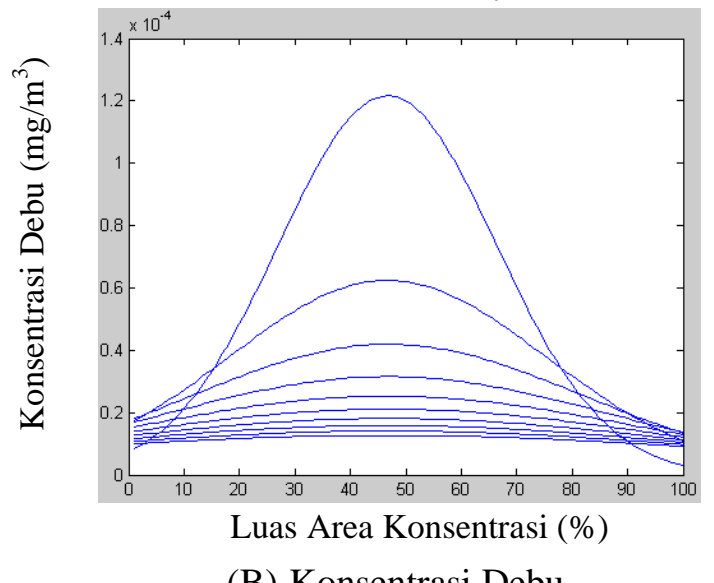

(B) Konsentrasi Debu

Gambar 9. Kontur Pola Penyebaran Desa Mojoruntut, dan (B). Konsentrasi Pengukuran Desa Lemujut Kelas F
Gambar 9 (A) menunjukkan kontur dan konsentrasi debu jarak pengukuran $\mathrm{x}=1800 \mathrm{~m}$ dari pusat cerobong pabrik gula Krembung yaitu Desa Lemujut pada stabilitas atmosfer $\mathrm{F}$ (stabil). Pada stabilitas atmosfer kelas F (stabil) ini pola penyebaran partikulat makin melebar dan jelas tiap segmennya dengan jumlah segmen degradasi warna enam. (B) Konsentrasi penyebaran lebih besar dibandingkan pada stabilitas atmosfer kelas A, B, C, D, dan E, yakni 1,25 x 10-4 dengan interval 0,2 x 10-4.

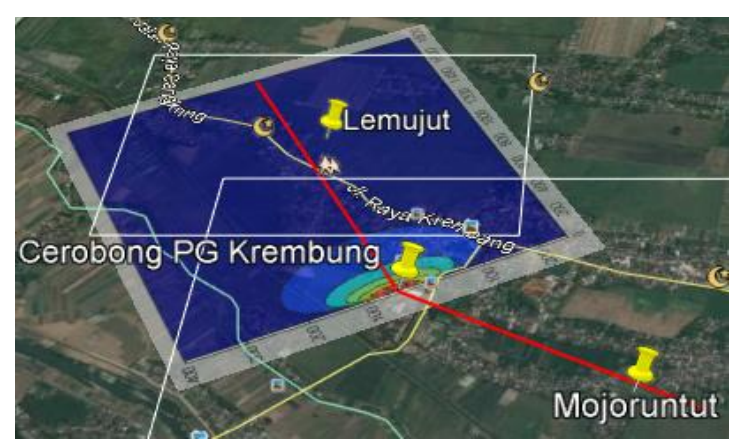

Gambar 10. Overlay Desa Mojoruntut

Gambar 10 menunjukkan overlay pengukuran di Desa Lemujut. Dari overlay menggunakan peta google earth dan pola kontur model dispersi gauss ini memperjelas area penyebaran debu dari pusat cerobong terhadap area pengukuran Desa Lemujut. Semakin jauh dari pusat cerobong Pabrik Gula Krembung makin kecil konsentrasi penyebaran debu yang jatuh di area tersebut.

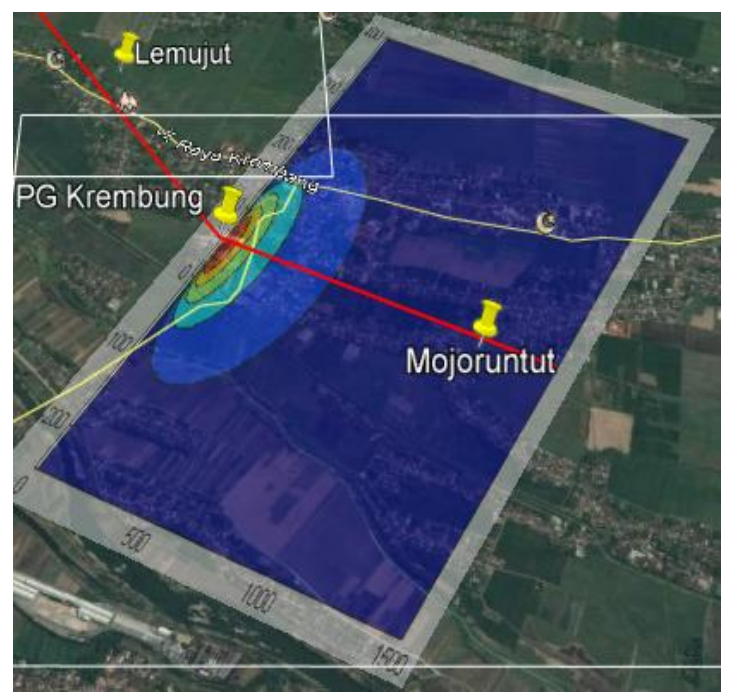

Gambar 11. Overlay Pengukuran 2 
Gambar 11 menunjukkan overlay pengukuran di Desa Mojoruntut. Hasil overlay dari peta google earth dan pola kontur model dispersi gauss jelas kelihatan area penyebaran debu dari pusat cerobong Pabrik Gula Krembung terhadap area pengukuran di Desa Mojoruntut. Semakin jauh dari pusat cerobong makin kecil konsentrasi penyebaran debu yang jatuh pada area tersebut.

\section{SIMPULAN}

Berdasarkan aplikasi alat ukur debu berbasis SMS gateway dan analisis model dispersi gauss dapat disimpulkan: Kelas stabilitas atmosfer pada model dispersi gauss dalam penyebaran debu sangat mempengaruhi model pola penyebaran. Pada jarak pengukuran yang berbeda, makin stabil kelas stabilitas atmosfernya pola penyebaran debu makin melebar dengan konsentrasi debu makin optimal. Aplikasi Alat ukur partikulat berbasis SMS gateway dapat bekerja secara optimal sesuai dengan perancangan, akan tetapi tetap dipengaruhi oleh kuatnya sinyal perangkat tekomunikasi saat pengukuran

\section{REFERENSI}

[1] Mukono, H.J. Pencemaran Udara dan Pengaruhnya Terhadap Gangguan Saluran Pernafasan. Surabaya: Airlangga University Press, 2008.

[2] Soedomo, Moestikahadi. Pencemaran Udara. Bandung : ITB, 2001.

[3] Ni Wayan Srimani Puspa Dewi, Tania June, Mochamad Yani, \& Mujito. Estimasi Pola Dispersi Debu, SO2 dan NOx dari Industri Semen Menggunakan Model Gauss yang Terintegrasi Dengan Screen 3. 1, 2018, Jurnal Pengelolaan Sumber Daya Alam dan Lingkungan, Vol. 8, pp. 109-119.

[4] S Syahrorini \& Mafatihul Akbar E.A. Alat Pendeteksi Debu Dengan Menggunakan Arduino Uno Dan Berbasis SMS Gateway. s.l.: Skripsi Teknik Elekrto Universitas Muhammadiyah Sidoarjo, 2017.

[5] S Syahrorini, A Rahmansyah, S H Pramono, \& Soemarno. Computer Simulation Of The Dispersion Gaussian Model Of Sugar Factory Particulate. s.1. : Asian Conference on Industrial Technology and Integrated Engineering (ACITIE2017), 2017. 